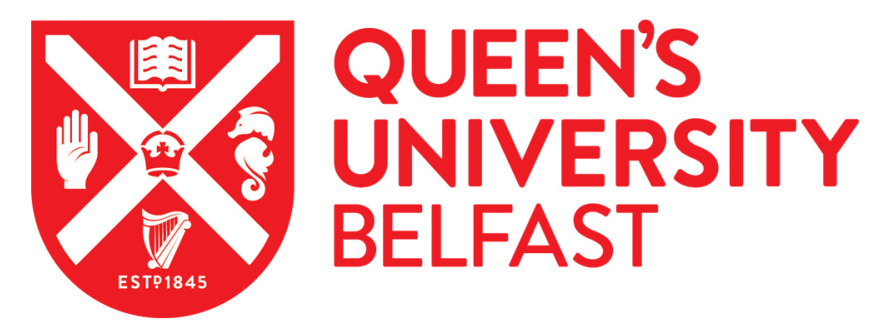

\title{
The joint effects of lead time, information sharing, and the accounts receivable period on reverse factoring
}

Huang, Q., Zhao, X., Zhang, M., yeung, K., Ma, L., \& Yeung, J. H-Y. (2019). The joint effects of lead time, information sharing, and the accounts receivable period on reverse factoring. Industrial Management and Data Systems, 120(1), 215-230. https://doi.org/10.1108/IMDS-04-2019-0228

Published in:

Industrial Management and Data Systems

Document Version:

Peer reviewed version

Queen's University Belfast - Research Portal:

Link to publication record in Queen's University Belfast Research Portal

Publisher rights

Copyright 2019 Emerald. This work is made available online in accordance with the publisher's policies. Please refer to any applicable terms of use of the publisher.

\section{General rights}

Copyright for the publications made accessible via the Queen's University Belfast Research Portal is retained by the author(s) and / or other copyright owners and it is a condition of accessing these publications that users recognise and abide by the legal requirements associated with these rights.

Take down policy

The Research Portal is Queen's institutional repository that provides access to Queen's research output. Every effort has been made to ensure that content in the Research Portal does not infringe any person's rights, or applicable UK laws. If you discover content in the Research Portal that you believe breaches copyright or violates any law, please contact openaccess@qub.ac.uk. 


\title{
The joint effects of lead time, information sharing, and accounts receivable period on reverse factoring
}

\begin{abstract}
:
Purpose - This study aims to empirically investigate the mechanisms through which lead time, information sharing, and accounts receivable period jointly affect reverse factoring adoption using a supplier's perspective.

Design/methodology/approach - Supported by one of the largest Chinese commercial banks, survey data are collected from 424 Chinese manufacturing firms and are analysed using regression methods.
\end{abstract}

Findings - The results suggest that lead time positively affects suppliers' reverse factoring adoption and the accounts receivable period. Meanwhile, information sharing has a positive influence on suppliers' reverse factoring adoption but negatively affects accounts receivable period. Accounts receivable period also positively affects suppliers' reverse factoring adoption.

Originality/value - The findings give suppliers and financial institutions a better understanding of how to leverage the benefits of reverse factoring.

Keywords Reverse factoring, Accounts receivable period, Lead time, Information sharing, Supply chain financing 


\section{Introduction}

Suppliers who have limited financial assets and are beholden to lengthy payment terms are making increasing use of various supply chain tools to mitigate the financial burden, optimize financial flows, and uncap profit growth potential. Reverse factoring (RF) is a widely acknowledged supply chain financing solution for improving working capital management (Zhang et al., 2019) and has been widely adopted by manufacturing firms in China. It offers suppliers access to short-term credit at a low cost through selling their accounts receivable to financial institutions at a reasonable discount in exchange for cash (Liebl et al., 2016; Caniato et al., 2019). By improving their working capital management through accounts receivable reduction, many suppliers can improve their profitability (Pezza, 2011; Liebl et al., 2016). This unique financial tool is likely to be increasingly considered by suppliers who either face financial pressure or require a faster cash conversion cycle (Liebl et al., 2016).

$\mathrm{RF}$ is not only a practical supply chain financing solution for suppliers, but also an important research topic in the supply chain finance literature (Liebl et al., 2016; Bals, 2019). The growing acceptance of this solution has not yet been accompanied by consensus on how suppliers make RF adoption decisions, nor the antecedents of RF adoption. Few empirical studies have investigated the factors impacting RF adoption from the supplier's perspective (Liebl et al., 2016). To further inform suppliers about this issue, we conducted a literature review and found that lead time, information sharing, and accounts receivable period are critical factors influencing suppliers' RF adoption. As such, this study aims to empirically investigate the joint effects of lead time, information sharing, and accounts receivable period on suppliers' RF adoption.

The findings can also enhance the understanding of how supply chain management practices are associated with manufacturers' RF adoption. Suppliers can obtain new 
financial value by taking advantages of lead time reduction and information sharing initiatives. Furthermore, suppliers can improve their investment in accounts receivable and strategic cooperation with buyers and financing institutions. In addition, our study can help financial institutions to better understand the conditions required for approving RF applications, which may significantly decrease their financial risk.

\section{Literature review}

RF is the widely acknowledged practice of supply chain finance in which suppliers can sufficiently sell or pledge their accounts receivable at a low interest cost with collaborative support of their buying clients (Grüter and Wuttke, 2017; Zhang et al., 2019). RF is essentially different from other types of supply chain financing solutions, such as purchase order financing, prepayment financing, inventory financing, and trade credit. It is a specific approach for financing suppliers' accounts receivable instead of other types of assets (Silvestro and Lustrato, 2014; van Der Vliet et al., 2015). Accordingly, it is requisite to consider the financial factor, accounts receivable period, to understand the antecedents of RF adoption. Account receivable period, also known as days of receivables or days sales outstanding, is essentially a proxy for assessing liquidity of accounts receivable (Silvestro and Lustrato, 2014; Carnovale et al., 2019). It refers to the number of days a supplier waits before receiving payments owed by their buying clients after delivery (Silvestro and Lustrato, 2014). Supported by Klapper (2006) and van der Vliet et al. (2015), poor liquidity of accounts receivable and subsequent capital pressure may prompt a supplier to adopt RF. The present study extends this research and investigates the direct effect of accounts receivable period on RF adoption.

Second, RF is subtly different from other similar supply chain financing solutions, such as factoring. RF is initiated by buyers to mainly support their strategic suppliers and 
secure their procurement (Liebl et al., 2016) rather than by suppliers themselves (Klapper, 2006). As such, it is critical to consider the operational factor, lead time, to unveil how suppliers with different levels of strategic abilities react to the option of RF. Lead time, a sufficient indicator measuring suppliers' abilities to improve customer responsiveness (Ponte et al., 2018), refers to the time span between customers' ordering and receiving products (Droge et al., 2004).

Third, RF is a multi-party arrangement involving both downstream and upstream supply chain firms, and external financial institutions (Liebl et al., 2016). Thus, it is important to consider the informational and technological factor, information sharing, to explore how information technology works in such an arrangement requiring complex interaction and communication. Information sharing refers to the informatization of a supply chain by implementing information technology enabled processes (Rai et al., 2006; Huo et al., 2013).

The literature review shows that the factors affecting supply chain financing adoption can be categorized into several dimensions (Marak and Pillai, 2018; Bals, 2019; Martin and Hofmann, 2019). Marak and Pillai (2018) argue that five types of factors (including financial, operational, technological, informational, and relational factors) affect supply chain financing adoption. Consistently, Bals (2019) conducts a thorough literature review and illustrates that scholars can develop a deeper understanding of supply chain financing adoption based on an eight dimension framework (including financial, supply chain collaboration, technology, and stakeholder perspective dimension, and so on). Martin and Hofmann (2019) report that three types of factors (including financial, cash flow-related, and relational factor) are highly related to suppliers' supply chain financing selection based on an exploratory multiple-case study. These scholars' findings suggest that four types of factors, including financial, operational, informational and technological as well 
as relational factors, can significantly influence adoption of supply chain financing. Based on the above proposed dimensions, we further enlist the following feasible factors after examining prior empirical literature.

- Financial Factors: Accounts receivable period, Availability of external financing;

- Operational Factors: Lead time, Frequency and volume of transactions;

- Informational and Technological Factors: Information sharing, Information visibility;

- Relational Factors: Collaboration, Dependence.

As for the financial factors, Wuttke et al. (2013) posit that a firm's working capital position (involving accounts receivable period) strongly affects its adoption of different types of supply chain financing solutions. Grüter and Wuttke (2017) clearly identify that RF is a supply chain financing arrangement leveraging accounts receivable. Bals (2019) concludes that the environment with restricted access to external financing contributes to the fast-growing field of supply chain finance.

Regarding the operational factors, Wang et al. (2019) verify that order fulfilment cycle, which is consistent with cumulative lead time, significantly impacts the adoption of accounts receivable finance, inventory finance, and accounts payable finance. Pezza (2011) clarifies that supply chain finance focuses on high frequency transactions. Wuttke et al. (2013) concentrate on suppliers with considerable procurement volume and financial supply chain management involvement.

As for the informational and technological factors, Caniato et al. (2019) highlight the role of real time information and digital technologies in improving information sharing along the supply chain and selecting the most suitable supply chain financing scheme. Song et al. (2016) report that information sharing in supply chains can significantly enhance firms' credit quality which facilitates their supply chain financing adoption. Pezza (2011) also emphasizes the role of information technology in providing online 
visibility into supply chain activities in the implementation of supply chain finance.

In respect to the relational factors, Grüter and Wuttke (2017) suggest that RF is arranged based on the close collaboration between buyers and suppliers. Carnovale et al. (2019) explore the implications of interdependence between supply chain firms on the implementation of the firms' supply chain financing initiatives and financial performance.

Given prior literature fragmentally suggests the above factors might affect supply chain financing adoption, this paper takes a step further to empirically verify how the most relevant, yet under-explored factors jointly affect RF, the widely acknowledged supply chain financing solution. Considering the unique characteristics of RF, this study focuses on three factors, including accounts receivable period, lead time, and information sharing.

Given that suppliers' RF adoption behaviours are the results of suppliers' financing needs of RF and banks' risk control (whether to approve suppliers' RF applications or not), many researchers suggest that lead time and information sharing can have both direct and indirect effects on a supplier's RF decisions. Considering banks' risk control, both lead time and information sharing are strongly related to supply chain collaboration and to suppliers' financial performance (Shi and Yu, 2013; Ponte et al., 2018; Şahin and Topal, 2019), subsequently facilitating the approval of suppliers' RF applications and ultimately leading to their adoption of RF.

Ponte et al. (2018) report that financial performance of supply chains was significantly sensitive to both the mean and the variability of lead times. Şahin and Topal (2019) state that information sharing has a significant and direct effect on firms' financial performance. Furthermore, suppliers' financing decisions are influenced by the risktaking behaviour of lending institutions (Stiglitz and Weiss, 1981). Suppliers who wish to pursue lower cost options available in the financial market may have their applications 
rejected in light of a high credit risk. This may be perceived through weaknesses in terms of long lead times and limited information-sharing, which usually indicates that suppliers may have difficulty in maintaining supply chain collaboration and positive financial performance (Altman and Saunders, 1998). Supported by this stream of literature, this study further investigates the direct effects of lead time and information sharing on RF adoption.

Considering suppliers' financing needs of RF, many studies suggest that improvement in lead time and information sharing may help suppliers improve accounts receivable liquidity (Shi and Yu, 2013; Şahin and Topal, 2019), thus relieving their financial pressure and reducing their financing requirements for RF adoption. Droge et al. (2004) imply that lead time highly relates to working capital position. Şahin and Topal (2019) support that information sharing significantly affects working capital position. Since working capital position is reflected by accounts receivable period (Wuttke et al., 2013), lead time and information sharing may influence accounts receivable period. Furthermore, as discussed above, accounts receivable period may directly influence RF adoption.

The literature review indicates that limited research has been conducted on how and why lead time, information sharing, and accounts receivable period are related to RF adoption. Research in this area is required to provide guidelines for suppliers on adopting RF. This study aims to fill this research gap by investigating joint effects of lead time, information sharing, and accounts receivable period on RF adoption.

\section{Research hypotheses}

\section{The effect of the accounts receivable period on reverse factoring}

A supplier's accounts receivable refers to the money that buyers have promised to pay 
for goods and services (van der Vliet et al., 2015). When exposed to a high risk of low liquidity, it is essential for suppliers to reduce their accounts receivable balances and improve their cash flow management (Grüter and Wuttke, 2017; Hautala et al., 2019). Suppliers are more likely to adopt RF in such circumstances, thus enabling the early collection of cash from sales at a discounted rate to improve the liquidity of their working capital (Richards and Laughlin, 1980; Klapper, 2006). In addition, when offering significant credit sales to customers, suppliers become vulnerable to liquidity issues because they need to manage their cash flow (including purchasing raw materials and paying wages) (Richards and Laughlin, 1980). Suppliers are more likely to adopt RF to release capital pressure by increasing accounts receivable liquidity and reducing negative effects of credit sales (Klapper, 2006). Therefore, we propose the following hypothesis.

\section{H1: Accounts receivable period is positively associated with RF adoption.}

\section{The effect of lead time on the accounts receivable period and reverse factoring}

To reduce lead time, suppliers must raise levels of collaboration and cooperation between their internal departments (e.g., purchasing, production, and marketing) and with their external supply chain partners (e.g., buyers) (Droge et al., 2004). Internal and external collaboration allow suppliers to reduce their operational costs and lead time (Cao and Zhang, 2011; Huo et al., 2013). When reducing lead time, a supplier can enhance its operational competence and the value of its products and services, thus increasing its power in a supply chain (Kim and Wemmerlöv, 2015). Suppliers with shorter lead times can then shrink the supply of trade credit by leveraging their power, thus reducing their accounts receivable period (Hautala et al., 2019). Therefore, we propose the following hypothesis.

H2: Lead time is positively associated with the accounts receivable period. 
Self-limiting lending behaviour occurs in financial institutions when they perceive a high level of credit risk. This high risk is usually a result of the adverse selection of highrisk suppliers (Stiglitz and Weiss, 1981). Suppliers may be able to relieve credit rationing when their financial prospects are more observable, or when their credit risk is more controllable from the lender's perspective (Altman and Saunders, 1998). With a shorter lead time, suppliers can respond more quickly to market changes and incur lower costs when meeting customer demand (Droge et al., 2004; Shi and Yu, 2013). Suppliers can thus engage in trustworthy supply chain transactions, allowing financial institutions to reduce risks (Klapper, 2006). Financial institutions typically raise the credit rating of suppliers that demonstrate shorter lead times when reviewing their RF applications. Based on the rationale that a shorter lead time can imply a higher capability, better financial prospects, and a more controllable credit risk (Altman and Saunders, 1998), it can be assumed that the willingness of financial institutions to approve suppliers' RF applications will be higher, and that the likelihood of a supplier adopting RF will be higher. Therefore, we propose the following hypothesis.

H3: Lead time is negatively associated with RF adoption.

\section{The effects of information sharing on the accounts receivable period and reverse}

\section{factoring}

Information sharing allows suppliers and buyers to speed up their cash-to-cash cycles along the entire supply chain, thus improving their working capital management (Richards and Laughlin, 1980; Kulp et al., 2004). Suppliers can quickly respond to the markets when they share operational information by making use of standardized information technologies (Handfield and Bechtel, 2002). Therefore, suppliers with a high level of information sharing usually have shorter cash-to-cash cycles due to better customer responsiveness and a faster collection of payments from customers (Silvestro 
and Lustrato, 2014). In addition, suppliers can reduce their accounts receivable balances because they can obtain timely financial and operational information and settle receivable balances (Rai et al., 2006; Silvestro and Lustrato, 2014). Therefore, we propose the following hypothesis.

H4: Information sharing is negatively associated with the accounts receivable period.

Financial institutions are difficult in distinguishing high quality loan clients from poor ones in the information asymmetric dilemma (Stiglitz and Weiss, 1981). Loan clients with risky ongoing projects are assumed to be more opportunistic in capturing all of the upside potentials of such projects (Bester, 1985). To reduce the RF credit risk, an effective strategy for financial institutions is to identify the credit risk inherent in suppliers' supply chain transactions and business operations on a real-time basis (Silvestro and Lustrato, 2014). Handfield and Bechtel (2002) and Kulp et al. (2004) support that information sharing improves supply chain transparency and provides financial institutions with realtime transaction information, which increases quality and quantity of the information available to them. Suppliers can collaborate with financial institutions by leveraging the available information systems to exchange timely information (e.g., in terms of sales, logistics, and financial data) (Rai et al., 2006), thus facilitating their RF applications. Such information sharing reduces information opacity and allows financial institutions to improve the quality and speed of their credit decision-making, enabling them to better manage their credit risk (Stiglitz and Weiss, 1981; Altman and Saunders, 1998). By analysing transaction information, financial institutions can identify qualified applicants more efficiently and effectively (Berger and Udell, 2006; Song et al., 2019). Therefore, we propose the following hypothesis.

H5: Information sharing is positively associated with RF adoption.

The research model is shown in Figure 1. 


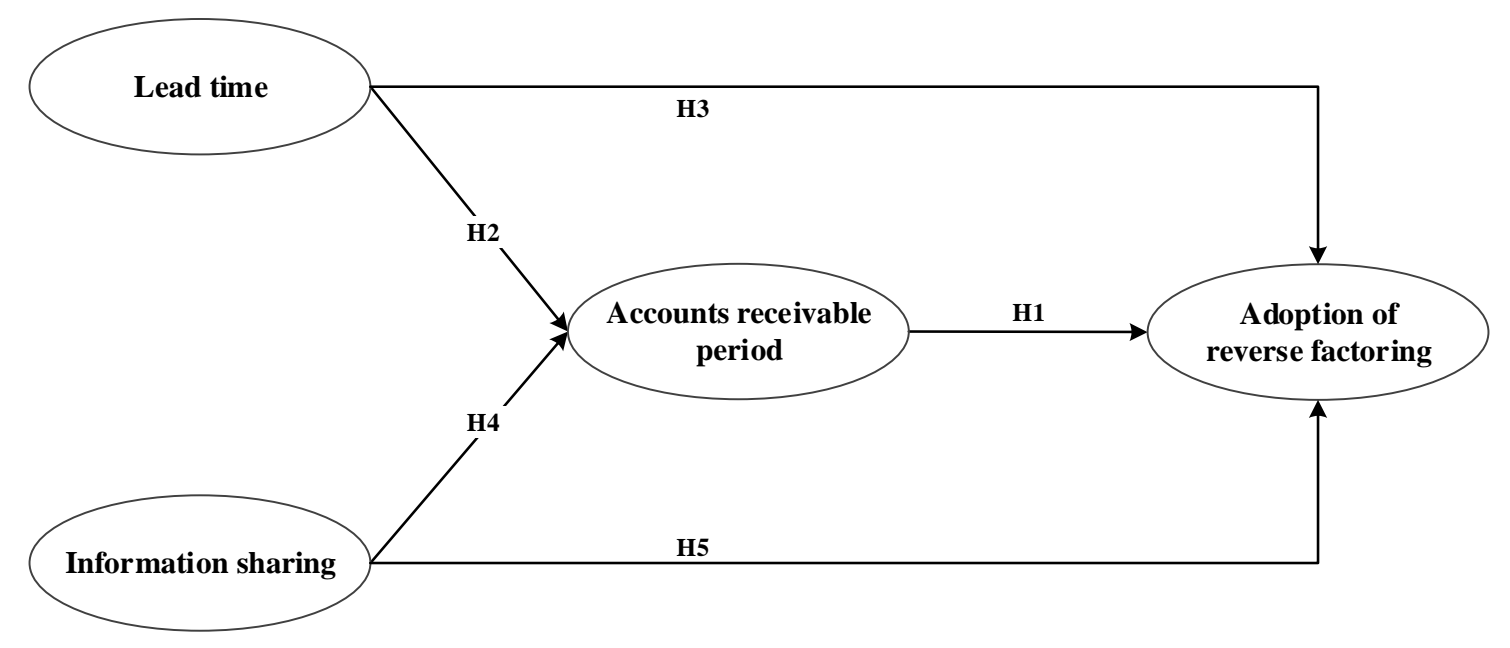

Figure 1. The research model

\section{Research methods}

\section{Variables}

The variables and their measurements are provided in Appendix A. Accounts receivable period is measured by the average number of days between delivery of goods and payment received, which enables us to take the time value of money into consideration (Randall and Theodore Farris II, 2009). Lead time refers to manufacturing lead time in this study and is measured by the average number of days starting from when customers order and ending with their receipt of the final products (Droge et al., 2004). Information sharing is measured by the degree of informatization and use of information technologies in supply chains (Rai et al., 2006; Huo et al., 2013). The adoption of RF is measured using a binary variable $(1=$ Yes; $0=$ No).

As reported above, this study adopts single-item indicators to measure corresponding constructs. According to Wanous and Hudy (2001), the reliability of single-item indicators should be somewhere between 0.7 and 0.9 . We justify the decision to use these indicators by the suggestions in the literature that they are acceptable and practical. Wanous et al. (1997) provide further support for the use of single-item indicators (such as accounts receivable period and lead time) as being practical and objective. The use of 
single items (such as information sharing) for clearly defined psychological constructs has also been found to be practical (Sackett and Larson, 1990). Thus, it is justifiable to use the single-item indicators for specific constructs in this study.

In addition, we add control variables including firm size, industry (Huo et al., 2013), and other types of working capital status such as accounts payable period, inventory turnover days of raw materials and finished goods (Zhang et al., 2019) in the data analyses. The measurements of the three control variables that reflect working capital status are: i) Accounts payable period or days of payables, which refers to the average number of days between receipt of products and payment (Randall and Theodore Farris II, 2009). ii) Inventory turnover days of raw materials/finished goods, which gauges a supplier's ability to efficiently turn its raw materials/finished goods into finished goods/sales, respectively. These were calculated by dividing the cost of goods sold by the average inventory value of the raw materials/finished goods and then multiplying by 365 days, respectively (Randall and Theodore Farris II, 2009). In addition, firm size is measured by annual sales.

\section{Data collection}

The survey was conducted in early 2018 with the support of one of the largest mainland commercial banks, which strives to improve customer services and revenue in the manufacturing sector. The questionnaire was designed by a group of supply chain financing experts. The pilot survey was conducted with the support of the top executives from 40 SME Chinese manufacturers. Based on their feedback, the questionnaire was revised and the survey questions shown in Appendix A were finalized.

The bank's database includes information on 6,920 RF corporate clients (i.e., suppliers). Stratified random sampling was conducted by dividing this population of 6,920 companies into the 9 industry groups of pharmaceutical, electronics, machinery, 
medical, steel, automobile, coal, food, and others. Three thousand companies were then randomly selected. With the help of the bank and five paid consultants, our research team members identified a list of key informants after communicating with their top management (such as CEOs) to request their support and commitment. Survey questionnaires were then sent by email to 621 committed companies and 517 companies returned their answered questionnaires by email. Different parts of the questionnaire were filled in by corresponding key informants, including financial directors, operations or supply chain managers, directors in information technology departments, and executives. We went through the data cleaning process and the responses with missing values were removed. A total of 424 complete and usable questionnaires were finally obtained, giving an effective response rate of $14.1 \%$ based on the number of companies contacted, which is considered acceptable, as a similar study by Huo et al. (2013) obtained 13.5\%. Around 90\% of these firms were from China's most developed areas (i.e., the Pearl River Delta, Yangzi River Delta, and Bohai Economic Rim). Approximately $80 \%$ of the companies had been collaborating with the bank for at least three years. Over $80 \%$ of the respondents had Bachelor's or postgraduate degrees.

We also evaluated non-response bias by comparing industry distribution and annual sales between the early and late respondents (Cao and Zhang, 2011). A chi-square test showed that there was no significant difference between them $(p>0.1)$, suggesting that non-response bias was not a problem. The sample distribution of the suppliers is shown in Table 1.

\section{$===$ Insert Table 1 here===}

Table 2 shows the descriptive statistics of the variables and their correlations. Among the 424 data samples, 137 of them (i.e., $32.3 \%$ of the suppliers) adopted RF. Using t-test for non-adoption $(\mathrm{Y}=0)$ and adoption $(\mathrm{Y}=1)$ independent samples, we identified the 
significant difference in mean values regarding accounts receivable period, lead time, and information sharing.

\section{$===$ Insert Table 2 here===}

We diagnosed the endogeneity by conducting a Durbin-Wu-Hausman augmented regression before testing the hypotheses (Davidson and MacKinnon, 2009). Specifically, we ran two Stage 1 models to predict lead time and accounts receivable period, respectively. We used a supplier's average relationship length with its major suppliers as an instrumental variable for lead time and a supplier's industry competitiveness as an instrumental variable for accounts receivable period (in the two stage 1 equations). The overall statistics summary and measurement of the two instrumental variables are shown in Table 2 and Appendix A, respectively. Theoretically, a supplier's average relationship length with its major suppliers might impact the supplier' lead time (Chen et al., 2004), but may not affect the supplier's RF adoption. A supplier's industry competitiveness might influence the supplier's accounts receivable period (i.e., their trade credit provision towards their customers) (Fisman and Raturi, 2004), but may not affect the supplier's RF adoption. We predicted the two residuals in two first stage regressions with lead time and accounts receivable period as the dependent variables, respectively. We included the two residuals in the second stage RF adoption equation and found that the two residuals in the second stage were both insignificant $(p=0.322>0.05$ and $p=0.467>0.05)$. Thus, we concluded that endogeneity is not an issue in our hypothesis testing.

\section{Analysis and results}

Regression analysis are conducted to test the hypotheses, and the results are presented in Table 3.

\footnotetext{
$===$ Insert Table 3 here $===$
} 
First, we conduct a binary logistic regression (Model 1) to test the ability of lead time, information sharing, and accounts receivable period to predict the probability of adopting RF. The $\chi 2$ test $($ chi-square $(0.001,15)=37.698<104.445)$ shows that the binary logistic regression is statistically significant and that the data fit the model well. The overall ability of the model to predict RF adoption is $75.5 \%$ (as shown in Table 3). The area under the ROC curve (AUC) is $0.787(\mathrm{p}<0.05)$, which suggests that the model has a high level of predictability, with an AUC value considered good if it lies between 0.7 and 0.9 .

The findings further reveal that accounts receivable period $(b=0.362$, Wald $=3.968$, $\mathrm{p}<0.05)$, lead time $(\mathrm{b}=0.422$, Wald $=10.124, \mathrm{p}<0.01)$, and information sharing $(\mathrm{b}=0.316$, Wald $=6.191, \mathrm{p}<0.05)$ significantly increase the probability of RF adoption. Therefore, $\mathrm{H} 1$ and $\mathrm{H} 5$ are empirically supported, while $\mathrm{H} 3$ is not supported. In addition, the results show that the accounts payable period negatively influences the probability of RF adoption, while annual sales has a positive influence. The probability of RF adoption is also significantly affected by industry type.

Second, we conduct a multivariate regression analysis (Model 2) to test the effects of lead time and information sharing on the accounts receivable period. The $\mathrm{F}$ test reveals that the model is statistically significant $(\mathrm{p}<0.001)$ and explains $28.4 \%$ of the variance in the accounts receivable period (as shown in Table 3). The results also show that lead time $(b=0.146, p<0.01)$ is positively associated with accounts receivable period. Meanwhile, information sharing $(b=-0.108, p<0.05)$ is negatively associated with accounts receivable period. Therefore, $\mathrm{H} 2$ and $\mathrm{H} 4$ are supported.

\section{Discussions and managerial implications}

This study provides solid insights and advices from which both suppliers (i.e., RF clients) and financial institutions can learn how to identify key characteristics that the desirable 
RF clients should have. Through better comprehension of desirable RF clients' characteristics and preference, suppliers can better position themselves and make the best use of internal and external resources when dealing with RF applications. Meanwhile, financial institutions' ability to develop comprehensive credit analytical variables is vital for their success of screening desirable clients and developing competitive RF services. To further fine-tune our findings and corroborate them, we have conducted ad hoc discussions with 2 senior managers of 2 scalable banks. They possess banking industry experience of 14 years and 13 years, respectively. Specifically, Bank A is an innovative and aggressive bank in China with an emphasis on big data development in its supply chain financing business. Bank B is a big traditional Chinese bank with ambition to expand the supply chain financing market. In the following, we will discuss the findings of our data analysis and ad hoc interviews.

\section{Lead time and reverse factoring adoption}

Contrary to initial expectation, the results illuminate that shorter lead time associated with suppliers' operations could account for lower probability of their RF adoption. It implies that suppliers with improved lead time performance tend not to borrow. Both Bank A and Bank B consensually prefer to select suppliers with short lead time as RF clients. However, in practice, they have not explicitly included lead time into their credit rating system due to their lack of professional knowledge in this field. It therefore necessitates to interpret the relationship between lead time and RF adoption purely from suppliers' perspective.

From suppliers' perspective, suppliers (i.e., potential RF clients) in general can improve their cash flow through implementing lead time reduction initiatives, which are the integral part of lean manufacturing. By making lean manufacturing investments, the suppliers generally can reduce inventory holding cost and improve customer 
responsiveness through shorter lead time. Given our novel findings that noticeably align with the lean manufacturing practices, we could further empirically elucidate the relationship between lead time and perceived financial values.

Our findings illuminate that suppliers can improve working capital management by improving the liquidity of accounts receivable through shortening lead time, which directly contributes to their financial performance. Subsequently, suppliers with short lead time prefer not to adopt RF due to the improvement of their internal abilities to solve their cash constraint problem in a cost effective way. Our findings show a clear clue to suppliers that, through shortening lead time, they can develop capability in improving their internal financial management, subsequently solving the cash constraint problem on their own instead of mitigating the issue through external RF facilities. Based on our findings, suppliers can realize the new financial value of short lead time and put more emphasis on short lead time to achieve the financial value. Also, our findings divulge that if suppliers have not improved lead time to address their cash constraint problems, they tend to rely on RF temporarily and sustain their operations through RF adoption.

\section{Information sharing and reverse factoring adoption}

In alignment with initial expectations, the results suggest that: (i) higher information sharing level could account for higher probability of suppliers' RF adoption; (ii) information sharing reduces accounts receivable period which is positively associated with probability of suppliers' RF adoption. Further substantiated by our ad-hoc interviews with Bank $\mathrm{A}$ and $\mathrm{B}$, we confirm that information sharing has mixed effects on RF adoption, which reflects two mechanisms through which information sharing affects RF adoption.

From suppliers' perspective, our findings suggest that suppliers (i.e. potential RF clients) are more likely to expand their avenue for external financing by leveraging high 
level of information sharing. Different from the traditional belief in the field of supply chain management that information sharing mainly contributes to production, our results propose that information sharing has significant financial value as well. On the one hand, through information sharing, suppliers can manage internal working capital by reducing accounts receivable period, subsequently managing their cash-to-cash cycle. On the other hand, facilitated by high level of information sharing, suppliers have a higher chance to access RF financing services without having to solely rely on their own financial capabilities.

From the financial institutions' perspective, according to Bank A and Bank B, when information sharing between suppliers and customers are extensive, the bank will generally hold a belief that: (i) the relationship between suppliers and customers is reliable, and (ii) their supply chain management practice is up to the standard. As such, due to the perception of lower risk, a bank's loan acceptance rate for suppliers with better information sharing will usually be higher than that of poor information sharing. Besides, due to sufficiency of information, a bank's credit line for suppliers with high information sharing level will usually be better aligned with their financing needs. According to the senior product manager of Bank A, different from past practices where credit loan officers set a small RF credit line, they usually provide sufficient amount of RF loans to satisfy the financing needs of suppliers with higher level of information sharing. As a result, by leveraging information sharing, banks can develop competitive RF services in which they can effectively control risks and meet suppliers' financing needs. Accordingly, suppliers with high information sharing level are more likely to become RF clients due to both higher probability to get RF loan approval and more willingness to adopt RF loans.

The general manager of Bank B, for instance, perceives suppliers' adoption behaviour as resulting from the influence of accounts receivable balances. According to Bank B, 
suppliers can diminish their needs for RF because they can reduce their accounts receivable balances by leveraging their high levels of information sharing to improve supply chain operations. Thus, the suppliers will be less motivated to adopt RF provided by Bank B. Based on the experience of Bank B's general manager, the direct effect of information sharing is normally much greater than the indirect effect through accounts receivable period as long as suppliers can easily and conveniently gain access to reasonable cost of financing to support their profitable project through information exchange.

\section{Conclusions}

In this study, the relationships between lead time, information sharing, accounts receivable period, and RF adoption are verified from the perspective of suppliers. The results reveal that lead time positively affects $\mathrm{RF}$ adoption and accounts receivable period. Information sharing has a positive and direct effect on RF adoption and a negative effect on accounts receivable period. Moreover, accounts receivable period is positively associated with RF adoption.

This study contributes to the literature by providing substantial and rigorous empirical evidence that lead time, information sharing, and account receivable period contribute to suppliers' decisions to adopt RF. This is a novel contribution to the supply chain management literature because operations and information technology are considered to be significant factors affecting financing behaviour (i.e., RF adoption). Our comprehensive survey of 424 manufacturers provides convincing evidence for the influences of these factors on suppliers' RF adoption. Thus, this study makes a significant contribution to the literature by extending the scope of RF adoption decision research to include the concepts of operations management and information sharing, while also 
considering the credit rationing. In summary, our study is novel because it investigates the issue of RF adoption through an empirical survey, and it explores how suppliers consider their survival and sustainable development when making an important supply chain financing decision (e.g., adopting RF). Unlike previous case studies (Liebl et al., 2016) and mathematical model research (van der Vliet et al., 2015; Grüter and Wuttke, 2017), this study provides strong empirical evidence for how and why suppliers make a supply chain financing decision and adopt a supply chain financing solution.

The study has limitations that provide avenues for future research. First, this paper highlights the three antecedents of RF adoption. Based on the significant influence of the financial factor (i.e., accounts receivable period), operational factor (i.e., lead time), and information and technological factor (i.e., information sharing) on RF adoption, scholars could endeavour to enrich the research scope and conceptual framework by systematically investigating the complicated impacts of the four types of factors on the adoption behaviour of various types of supply chain financing in future research. Second, as revealed in our findings, information sharing, which is an imperative supply chain practice facilitated by information technology, complicatedly affects firms' financial management. As highlighted by scholars in the field of supply chain financing, the effects of information technology would be much more extensive in terms of customer analytics, advisory, credit process automation, authenticity, cross-border collaboration and so on. In further research, scholars may concentrate on the value chain (from front line to midoffice and back office) of supply chain financing service providers and further analyse the impact of state-of-art information technology (such as artificial intelligence, blockchain technology) on the supply chain financing practices (such as FinTech as supply chain financing service) and customer behaviour. 


\section{References}

Altman, E. and Saunders, A. (1998), “Credit risk measurement: developments over the last 20 years", Journal of Banking and Finance, Vol. 21 No. 11-12, pp. 1721-1742.

Bals, C. (2019), “Toward a supply chain finance (SCF) ecosystem - proposing a framework and agenda for future research”, Journal of Purchasing and Supply Management, Vol. 25 No. 2, pp. 105-117.

Berger, A. N. and Udell, G. F. (2006), “A more complete conceptual framework for SME finance”, Journal of Banking and Finance, Vol. 30 No. 11, pp. 2945-2966.

Bester, H. (1985), “Screening vs. rationing in credit markets with imperfect information', The American Economic Review, Vol. 75 No. 4, pp. 850-855.

Caniato, F., Henke, M. and Zsidisin, G. A. (2019), "Supply chain finance: historical foundations, current research, future developments", Journal of Purchasing and Supply Management, Vol. 25 No. 2, pp. 99-104.

Cao, M. and Zhang, Q. (2011), "Supply chain collaboration: impact on collaborative advantage and firm performance", Journal of Operations Management, Vol. 29 No. 3, pp. 163-180.

Carnovale, S., Rogers, D. S. and Yeniyurt, S. (2019), "Broadening the perspective of supply chain finance: The performance impacts of network power and cohesion". Journal of Purchasing and Supply Management, Vol. 25 No. 2, pp. 134-145.

Chen, I. J., Paulraj, A. and Lado, A. A. (2004), "Strategic purchasing, supply management, and firm performance", Journal of Operations Management, Vol. 22 No. 5, 505-523.

Davidson, R. and MacKinnon, J.G. (2009), Econometric Theory and Methods. Oxford University Press, New York. 
Droge, C., Jayaram, J. and Vickery, S. K. (2004), “The effects of internal versus external integration practices on time-based performance and overall firm performance”, Journal of Operations Management, Vol. 22 No. 6, pp. 557-573.

Fisman, R. and Raturi, M. (2004), "Does competition encourage credit provision? Evidence from African trade credit relationships", Review of Economics and Statistics, Vol. 86 No. 1, pp. 345-352.

Grüter, R. and Wuttke, D. A. (2017), “Option matters: valuing reverse factoring", International Journal of Production Research, Vol. 55 No. 22, pp. 6608-6623.

Handfield, R. B. and Bechtel, C. (2002), “The role of trust and relationship structure in improving supply chain responsiveness", Industrial Marketing Management, Vol. 31 No. 4, pp. 367-382.

Hautala, P., Lorentz, H. and Töyli, J. (2019), "Value chain perspective on the use of trade credit during the 2006 - 2015 business cycle - evidence from Eurozone SMEs”, International Journal of Logistics Research and Applications, Vol. 22 No. 2, pp. 204-227.

Huo, B., Han, Z., Zhao, X., Zhou, H., Wood, C. H. and Zhai, X. (2013), “The impact of institutional pressures on supplier integration and financial performance: evidence from China”, International Journal of Production Economics, Vol. 146 No. 1, pp. 82-94.

Kim, Y. H. and Wemmerlöv, U. (2015), “Does a supplier's operational competence translate into financial performance? An empirical analysis of supplier-customer relationships", Decision Sciences, Vol. 46 No. 1, pp. 101-134.

Klapper, L. (2006), "The role of factoring for financing small and medium enterprises", Journal of Banking and Finance, Vol. 30 No. 11, pp. 3111-3130. 
Kulp, S. C., Lee, H. L. and Ofek, E. (2004), "Manufacturer benefits from information integration with retail customers", Management Science, Vol. 50 No. 4, pp. 431-444.

Lieb1, J., Hartmann, E. and Feisel, E. (2016), "Reverse factoring in the supply chain: objectives, antecedents and implementation barriers", International Journal of Physical Distribution and Logistics Management, Vol. 46 No. 4, pp. 393-413.

Marak, Z. and Pillai, D. (2018). "Factors, outcome, and the solutions of supply chain finance: review and the future directions", Journal of Risk and Financial Management, Vol. 12 No. 1, pp. 1-23.

Martin, J. and Hofmann, E. (2019), “Towards a framework for supply chain finance for the supply side", Journal of Purchasing and Supply Management, Vol. 25 No. 2, pp. $157-171$.

Pezza, S. (2011). "Supply chain finance: Gaining control in the face of uncertainty", Technical Report Aberdeen Group. Retrieved from http://www.aberdeen.com.

Ponte, B., Costas, J., Puche, J., Pino, R. and de la Fuente, D. (2018), “The value of lead time reduction and stabilization: a comparison between traditional and collaborative supply chains", Transportation Research Part E: Logistics and Transportation Review, Vol. 111 No. March, pp. 165-185.

Rai, A., Patnayakuni, R. and Seth, N. (2006), "Firm performance impacts of digitally enabled supply chain integration capabilities”, MIS Quarterly, Vol. 30 No. 2, pp. 225-246.

Randall, W. S. and Theodore Farris II, M. (2009), "Supply chain financing: using cashto-cash variables to strengthen the supply chain", International Journal of Physical Distribution \& Logistics Management, Vol. 39 No. 8, pp. 669-689.

Richards, V. D. and Laughlin, E. J. (1980), “A cash conversion cycle approach to liquidity analysis”, Financial Management, Vol. 9 No. 1, pp. 32-38. 
Sackett, P. R. and Larson, J. R. (1990), Research strategies and tactics in industrial and organizational psychology, Consulting Psychologists Press, Palo Alto, CA.

Şahin, H. and Topal, B. (2019), "Examination of effect of information sharing on businesses performance in the supply chain process", International Journal of Production Research, Vol. 57 No. 3, pp. 815-828.

Shi, M. and Yu, W. (2013), "Supply chain management and financial performance: literature review and future directions", International Journal of Operations and Production Management, Vol. 33 No. 10, pp. 1283-1317.

Silvestro, R. and Lustrato, P. (2014), "Integrating financial and physical supply chains: the role of banks in enabling supply chain integration", International Journal of Operations and Production Management, Vol. 34 No. 3, pp. 298-324.

Song, H., Lu, Q., Yu, K. and Qian, C. (2019), “How do knowledge spillover and access in supply chain network enhance SMEs' credit quality?”, Industrial Management \& Data Systems, Vol. 119 No. 2, pp. 274-291.

Song, H., Yu, K., Ganguly, A. and Turson, R. (2016), "Supply chain network, information sharing and SME credit quality”, Industrial Management \& Data Systems, Vol. 116 No. 4, pp. $740-758$.

Stiglitz, J. E. and Weiss, A. (1981), "Credit rationing in markets with imperfect information", American Economic Review, Vol. 71 No. 3, pp. 393-410.

van der Vliet, K., Reindorp, M. J. and Fransoo, J. C. (2015), “The price of reverse factoring: financing rates vs. payment delays", European Journal of Operational Research, Vol. 242 No. 3, pp. 842-853.

Wang, Z., Wang, Q., Lai, Y., and Liang, C. (2019). Drivers and outcomes of supply chain finance adoption: An empirical investigation in China. International Journal of Production Economics, Upcoming. 
Wanous, J. P. and Hudy, M. J. (2001), "Single-item reliability: A replication and extension”, Organizational Research Methods, Vol. 4 No. 4, pp. 361-375.

Wanous, J. P., Reichers, A. E. and Hudy, M. J. (1997), “Overall job satisfaction: how good are single-item measures? ", The Journal of Applied Psychology, Vol. 82 No. 2, pp. 247-252.

Wuttke, D. A., Blome, C. and Henke, M. (2013), "Focusing the financial flow of supply chains: an empirical investigation of financial supply chain management", International Journal of Production Economics, Vol. 145 No. 2, pp. 773-789.

Zhang, T., Zhang, C. Y. and Pei, Q. (2019), “Misconception of providing supply chain finance: its stabilising role", International Journal of Production Economics, Vol. 213 No. July, pp. 175-184. 


\section{Appendix A: Variables and measurements}

Adoption of RF Please indicate whether your company adopts reverse factoring.

Accounts receivable period Please indicate your company's average days of accounts receivable (range from 1 to 4 ).

1: Less than 15 days; 2: 15 to 44 days; 3: 45 days to 89 days; 4: 90 days or more.

Lead time Please indicate your company's manufacturing cycle (range from 1 to 5).

1: Less than 7 days; 2: 7 days to 29 days; 3: 30 days to 59 days; 4: 60 days to 119 days; 5: 120 days or more.

Information sharing Please indicate the extent of supply chain informatization and the use of information technologies between your organization and your major customers (1-Not at all; 4-Extensively).

Relationship length Please indicate how long your company has collaborated with your company's major suppliers (range from 1 to 4).

1: Less than 1 year; 2: 1 year to 3 years; $3: 3$ years to 5 years; $4: 5$ years or more.

Industry competitiveness Please indicate the competition level in your industry (1Very intensive; 2-intensive; 3-Moderate). 